\title{
Restaurante popular: a política social em questáo
}

\section{| ${ }^{1}$ Susana Moreira Padrão, ${ }^{2}$ Odaleia Barbosa de Aguiar |}

Resumo: As políticas públicas sociais são reconhecidas, nesse ensaio, como imperativas, nos marcos das sociedades capitalistas, para materialização de direitos e necessidades humanas. No Brasil, e nos demais países capitalistas, as políticas sociais se instituíram como desdobramento das lutas de classe, caminho para a conquista de direitos e diminuição de desigualdades. No entanto, dependentes da liberação de recursos públicos, mostram-se fragmentadas e descontínuas. No que tange às políticas sociais, no âmbito da segurança alimentar e nutricional, o Programa de Rede de Equipamentos Públicos de Segurança Alimentar e Nutricional, com destaque para os restaurantes populares, tem como objetivo promover o acesso da populaçáo urbana à alimentação adequada, a preços acessíveis, com prioridade aos segmentos mais vulneráveis. Nascidos sob a égide da desigualdade social, originalmente na década de 1940, continuam sendo utilizados para minimizar desajustamentos políticos, sociais e econômicos. A contribuição efetiva desses restaurantes é amenizar a situação de insegurança alimentar, entretanto a irregularidade dos recursos públicos e a restrita participação e controle sociais podem comprometer a execução da política social e a materialização do direito humano à alimentação. O fechamento dos 16 restaurantes, em 2016, no Rio de Janeiro, significou abrir mão do atendimento emergencial e da necessária proteção social.

> Palavras-chave: política social; Segurança Alimentar e Nutricional; restaurantes; setor público; assistência alimentar.

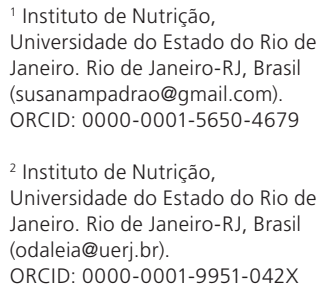

1 Instituto de Nutrição, Universidade do Estado do Rio de Janeiro. Rio de Janeiro-RJ, Brasil (susanampadrao@gmail.com). ORCID: 0000-0001-5650-4679

${ }^{2}$ Instituto de Nutrição,

Universidade do Estado do Rio de Janeiro. Rio de Janeiro-RJ, Brasil (odaleia@uerj.br). ORCID: 0000-0001-9951-042X 


\section{Introdução}

No debate da política pública social, na sociedade capitalista, examinar o papel do Estado como regulador e mediador da relação entre capital e trabalho torna-se relevante para compreender a política como meio de manutençáo da ordem vigente. Não obstante, esmiuçar o papel das classes sociais, como protagonistas na conquista de direitos, em diferentes contextos sociais e históricos, parece-nos imprescindível para compreensão da materialização de direitos sociais.

A gênese dos direitos sociais não ocorreu de forma isolada na sociedade do capital, mas no seio dos processos de luta por um conjunto de direitos que atenuassem as desigualdades expressas pela questão social, ${ }^{1}$ no final do século XIX na Europa. A partir da fase monopolista ${ }^{2}$ do capitalismo, no início do século XX, o Estado capitalista altera sua natureza, para além de suas atribuiçóes econômicas, que asseguravam as condições para reprodução do modo de produção capitalista. Assume funçôes de regulação e mediação de políticas públicas, passando a atender, em alguma medida, aos interesses da classe trabalhadora. Essa mudança foi provocada pelo cenário de crescimento econômico e industrialização, que impulsionou a ampliação do movimento operário, dos sindicatos de trabalhadores, facilitando a organização e a participação política desses sujeitos, que passaram a exigir do Estado açôes que garantissem direitos políticos e sociais. ${ }^{3}$ A conjunção desses fatores tornou o Estado mais permeável às demandas e interesses da classe trabalhadora, que passou a concertar ações de coerção com políticas de caráter social, visando obter um consenso imprescindível à acumulação do capital (MARCONSIN, 2007).

Destaca-se a falta de consenso em relaçáo ao significado atribuído ao termo política pública social, cujos diferentes conceitos se estabelecem a partir de posiçôes ideológicas, valores e perspectivas teóricas específicas. Para a reflexão aqui proposta, importa apontar a compreensão da política social que serviu de fundamento para a discussão do programa social de alimentação em pauta. Nesse sentido, entende-se a política social como uma ação que:

[...] visa, mediante esforços organizado e pactuado, atender necessidades sociais cuja resolução ultrapassa a iniciativa privada, individual e espontânea, e requer deliberada decisão coletiva regida por princípios de justiça social que, por sua vez, devem ser amparados por leis impessoais e objetivas, garantidoras de direitos (PEREIRA, 2009, p. 171).

Importa, ainda, indicar algumas características que devem ser asseguradas, na formulação, no planejamento e na execução das políticas sociais, para que sejam 
capazes de influir na realidade concreta em que se inserem. Seu caráter público deve ser garantido, o que significa atender ao interesse comum sem distinção, visando a demandas sociais e não individuais, nem à rentabilidade econômica e privada. O princípio da universalidade, também, deve ser afiançado, pois se tratando do atendimento a um direito o acesso deve ser universal e sempre facilitado, sem mecanismo de seletividade ou focalização. Tendo como objeto as necessidades sociais, não pode prescindir da participação da sociedade, nas decisões e escolhas, e do controle social e democrático, através dos movimentos sociais organizados.

Nos marcos das sociedades capitalistas, a política social permanece atrelada à capacidade de organizaçáo das classes sociais, estando longe de se encerrar em uma tensão bipolar, entre Estado e movimento social, considerando que abarca diferentes sujeitos e, muitas vezes, interesses antagônicos, o que lhe imprime uma forma dialeticamente contraditória. Por estar subordinada às políticas de governo e à correlação de forças envolvida nos processos de decisão fica sempre sujeita a descontinuidades e retrocessos. Regulada e provida pelo Estado, mantém-se dependente da liberação de recursos públicos, podendo ter sua gestão descentralizada, o que implica fortalecer uma tendência à desresponsabilização. ${ }^{4}$ Como ação pública, compromete tanto o Estado, que tem o dever de garantir direitos, quanto à sociedade civil organizada, através de suas representaçôes que atuam em defesa dos interesses de classe e no controle social, buscando influenciar no formato, no conteúdo e na abrangência dos programas sociais (PEREIRA, 2009).

Nessa perspectiva, reconhecemos a política pública social como imperativa, nos marcos da acumulação capitalista, para materializar direitos, necessidades humanas e demandas imediatas, na expectativa da cidadania ampliada, que contribuam para melhorar as condiçóes de trabalho e de vida da classe trabalhadora. Esse posicionamento, entretanto, não deve superestimar as possibilidades da política na superação da situação de vulnerabilidade da existência material do conjunto dos trabalhadores, nem, tampouco, inibir ou paralisar a luta na perspectiva da emancipação política e humana, que apenas se concretizará com o fim da exploração do homem pelo próprio homem.

Este ensaio se propóe a avaliar o programa social dos restaurantes populares no Estado do Rio de Janeiro, no âmbito da política de Segurança Alimentar e Nutricional (SAN), que busca, entre outros objetivos, assegurar o direito humano 
à alimentação adequada a toda população, diminuindo situaçôes de insegurança alimentar e de fome nos segmentos mais vulneráveis da população.

\section{Política de Segurança Alimentar e Nutricional: do combate à fome ao direito humano à alimentação}

No Brasil, as políticas públicas sociais, em especial na área de alimentação e nutrição, instituíram-se reguladas pelo Estado, que exerce o papel de mediador com a expectativa de manter sua legitimidade e asseverar a estabilidade social. Dependentes da liberação dos recursos públicos, mostram-se, como consequência, fragmentadas e descontínuas, desde quando foram estabelecidas, nos anos 1940.

Um longo e acidentado caminho foi percorrido até a construção de um marco legal e jurídico que, no cenário atual, possibilitasse a sustentação de açóes no âmbito da segurança alimentar e nutricional (SAN), na perspectiva de tornar o acesso permanente e universal à alimentação adequada um direito humano. Até então, no conjunto dos programas sociais implantados, com pequenas variaçôes, as açôes se limitavam a iniciativas de suplementação alimentar, distribuição e subsídios para alimentos e refeiçôes prontas que atendiam a segmentos específicos, além de fartos e diversificados materiais de orientação, recomendação e educação nutricional, com forte viés ideológico, pois tendiam a culpabilizar os indivíduos pelo seu estado de saúde e nutricional.

Não foram identificadas, na revisão realizada para elaboração da síntese histórica das políticas de alimentação e nutrição, iniciativas que conjugassem, por exemplo, o aumento da produção e distribuição de alimentos com uma reforma agrária que facilitasse o acesso aos alimentos, incentivando o cultivo familiar e local da terra. Da mesma forma, não foi observada qualquer proposição para uma reforma tributária, que promovesse medidas de caráter redistributivo, beneficiando a classe trabalhadora. Ações que seriam viáveis, mesmo nos marcos do processo de acumulação capitalista, mas que tendendo a reduzir lucros e acirrar a disputa pelo fundo público, são difíceis de serem acionadas, uma vez que o Estado tende, preferencialmente, a assegurar as condiçốes de acumulação e favorecer o capital (BEHRING, 2009). Em vez de iniciativas que imprimissem maior justiça social, prevaleceu a perspectiva que reduziu os problemas alimentares e nutricionais a questôes relacionadas à pobreza e à fome, intervindo estritamente no consumo sem interferir na cadeia alimentar e produtiva. 
Este moroso trajeto pode ser compreendido, em grande medida, pelo fato de a questão alimentar só ter sido efetivamente incorporada como pauta dos movimentos sociais e dos trabalhadores organizados, e, portanto, como elemento de mobilização, capaz exercer pressão, a partir da década de 1980. Apesar de a fome ${ }^{5}$ ser reconhecida como um problema social no Brasil, e no mundo, desde a década de 1940, as políticas sociais implantadas para enfrentar os problemas alimentares cumpriam, de fato, o papel de atenuar conflitos e como mecanismos para garantir a legitimidade e a hegemonia do Estado (VASCONCELOS, 2005).

Não obstante, após esse breve período de conquistas, o fortalecimento do projeto neoliberal, no início dos anos 1990, provocou a extinção de órgãos públicos federais e a redução de recursos para programas sociais, justificadas pela necessidade de modernização do Estado (LEÃO; CASTRO, 2007). A consequência foi a descontinuidade de políticas sociais que promoviam alguma forma de proteção social, consequência também da correlação de forças desfavorável à classe trabalhadora. As ações pontuais e compensatórias passaram a se constituir como prioridade, para atender aos segmentos vulneráveis da população.

Nesse processo de descontinuidades de políticas, com contrarreformas orientadas para atender ao mercado, promovidas a partir de 1994 (BEHRING; BOSCHETTI, 2010), foi extinto o Instituto Nacional de Alimentação e Nutrição (INAN), órgão responsável pela coordenação e acompanhamento dos programas da área de alimentaçáo e nutrição. Não obstante, a extinção do INAN foi precedida por um movimento de enfrentamento e resistência, protagonizado por técnicos do órgão, na perspectiva de evitar seu fechamento. Essa mobilização acabou fomentando o debate acerca da elaboração de uma política nacional de alimentação e nutrição. Após processo de ampla discussão, foi aprovada pelo Conselho Nacional de Saúde, em 1999, a Política Nacional de Alimentação e Nutrição (PNAN). A PNAN apresenta avanços do ponto de vista do atendimento aos direitos sociais, salienta a importância da construção de uma Política de Segurança Alimentar e Nutricional (JAIME et al., 2011) e incorpora a defesa do Direito Humano à Alimentação Adequada (DHAA). A partir do ano 2000, é observada uma mudança na forma de operacionalização de programas na área de alimentação e nutrição, que passam a operar, também, através da transferência direta de renda, substituindo, principalmente, as açôes de distribuição de alimentos (PINHEIRO, 2008). Destaca-se, nesse formato, o 
Programa Nacional de Renda Mínima, vinculado ao Ministério da Saúde, criado em agosto de 2001, denominado como Bolsa Alimentação (PBA).

A reconstituição do CONSEA, em 2003, que havia sido extinto em 1996, também impulsionou açôes na área da segurança alimentar e nutricional. Fomentar e aprofundar o debate e a articulação entre governo e sociedade civil tem sido papel destacado desse conselho. $\mathrm{O}$ papel de fiscalizaçáo da política, a ampliação do controle social, assim como a organização de Conferências Nacionais de Segurança Alimentar e Nutricional (CNSAN), cuja 5a edição foi realizada em 2015, também podem ser apontadas como atribuiçóes relevantes do conselho. Foi durante a $2^{\text {a }}$ Conferência Nacional de Segurança Alimentar e Nutricional, em 2004, que o conceito de SAN foi construído e os fundamentos da Lei Orgânica de Segurança Alimentar e Nutricional (LOSAN) foram discutidos e definidos. Dois anos depois, em setembro de 2006, a lei é aprovada pelo Congresso Nacional. A LOSAN incorpora a garantia do Direito Humano à Alimentação Adequada (DHAA) como um dever do Estado, a quem cabe respeitar, proteger, promover e prover este direito (BRASIL, 2006).

O avanço apresentado pela LOSAN, além da construção de um conceito de SAN amplo e transversal, ${ }^{6}$ expressa-se na formalização de um Sistema Nacional de Segurança Alimentar e Nutricional (SISAN). O SISAN é definido como um sistema suprassetorial e aberto, com a atribuição de promover e implantar políticas e planos de segurança alimentar e nutricional, articulando ações de instâncias governamentais e não governamentais, de diferentes esferas (PINHEIRO, 2008). Em 2010, dando continuidade à formulação de açôes de SAN, institui-se a Política Nacional de Segurança Alimentar e Nutricional (BRASIL, 2010), que designa mecanismos de adesão ao SISAN, por parte de estados, municípios e entidades privadas, com ou sem fins lucrativos, afetas à SAN, além de definir pactos, intersetorial e interfederal, para consolidação do sistema (SANTARELLI, 2012). Entretanto, tem sido observada uma baixa adesão ao SISAN, em particular, pelos municípios no país. São 233 prefeituras, sendo 11 capitais de estados, que participam do sistema, em um universo de mais de 5.000 municípios. No Estado do Rio de Janeiro, por exemplo, apenas dois municípios aderiram até o momento ao sistema, os municípios de Volta Redonda e Duque de Caxias. A expectativa é que até 2019, seiscentos municípios participem do sistema (BRASIL, 2017).

Merece, ainda, destaque, como um fato político importante, a aprovação da emenda constitucional que incorpora ao artigo $6^{\circ}$ da Constituição Federal, o 
Direito Humano à Alimentação Adequada (DHAA), como um direito universal e fundamental, de todos os residentes em território nacional. A efetivação desse pleito estabelece mecanismos legais para a exigibilidade desse direito e procura ultrapassar iniciativas compensatórias que foram prioridade durante todo esse percurso.

No decorrer desse período, a partir de 2003, diversas açóes e programas de SAN foram desenvolvidos e ampliados, iniciativas que suplantaram a esfera do Ministério da Saúde, cujas ações se fundamentam nas diretrizes da Política Nacional de Alimentação e Nutrição (2012) com ênfase no Sistema Único de Saúde (SUS). Outros ministérios passam a ter como foco açóes e projetos voltados à segurança alimentar e nutricional (SAN), com destaque para o Ministério de Desenvolvimento Agrário e o Ministério de Desenvolvimento Social e Combate à Fome (MDS7). O MDS tem planejado e coordenado programas que impactam, direta ou indiretamente, a SAN. O Programa Bolsa Família, que prevê a transferência direta de recursos a famílias em estado de maior vulnerabilidade, e o Programa de Aquisição de Alimentos (PAA), que prioriza a compra de alimentos diretamente do agricultor familiar e os destina aos grupos em situação de insegurança alimentar, são algumas dessas iniciativas.

As políticas sociais instituídas nesse período, em grande medida, estabeleceram uma maior interlocução e articulação com os movimentos sociais, em particular, com a mediação dos Conselhos de Segurança Alimentar e Nutricional (CONSEA), das diferentes esferas da federação em suas formulações. Os programas se distinguem pelo fato de não se restringirem a açôes de suplementação, distribuição ou consumo de alimentos, que quando desenvolvidas de forma isolada não alteram a situação de carência dos beneficiados, apesar de importantes e, muitas vezes, imprescindíveis. É importante, ainda, ressaltar que as políticas de SAN incorporaram a necessidade e a possibilidade de um controle social mais democrático, através da instituição de conselhos, em especial os CONSEA, com a função de fiscalização, além da ampliação do alcance da proteção social e maior constância na liberação de recursos, o que gerou maior estabilidade na execução dos programas. Entretanto, a universalização das ações não tem sido uma característica contemplada, nem mesmo o atendimento universal nos limites definidos pelos próprios critérios de seletividade estabelecidos pelos programas (STEIN, 2009).

Para a discussão proposta neste estudo, interessa destacar, dentre as iniciativas desenvolvidas no âmbito da política de SAN, o programa dos restaurantes populares 
(RP), que integra a Rede de Equipamentos Públicos de Segurança Alimentar e Nutricional, composta, ainda, pelas cozinhas comunitárias e os bancos de alimentos.

\section{Restaurantes populares: um programa social no âmbito da SAN}

Os restaurantes populares (RP) nasceram sob a égide da desigualdade social e continuam sendo utilizados pelos governos de diversos países para minimizar os desajustamentos políticos, sociais e econômicos, expressôes da questão social. Essas políticas sociais evidenciam as desigualdades econômicas e sociais que atingem os trabalhadores e as dificuldades de acesso dos mesmos a alimentação permanente e adequada.

Quando de seu surgimento, para Costa (1947) os restaurantes poderiam estimular novas iniciativas de produçáo agrícola. Entretanto, era no terreno da educação alimentar, em que a família era o principal alvo da ação dos restaurantes, que se detinha o maior interesse na implantação desses equipamentos, isto é, formação de novos hábitos alimentares. Os idealizadores da alimentação pública acreditavam na possibilidade de intervir nas condiçôes alimentares do povo, com a adoção de novos hábitos alimentares, ensinando a boa alimentação pelo exemplo, na lição prática da ração cientificamente balanceada e agradavelmente preparada para os trabalhadores. O fato de servir um cardápio fixo, que incluíam alimentos variados, de verdura ao leite, da carne às frutas, os RP estariam mostrando na prática, aos seus frequentadores, como realizar uma alimentação adequada, saborosa e correta, familiarizando-os com um extenso número de alimentos e os habituando ao consumo de alimentos que anteriormente eram recusados ou simplesmente não existiam à mesa habitual (COSTA, 1947).

Esta forma de abordar hábitos alimentares considerados inadequados, que por muito tempo prevaleceu nas ações de educação nutricional, priorizava o desconhecimento e a falta de informaçáo como principal causa das carências e problemas nutricionais. Estas iniciativas, muitas vezes, desconsideram, ou negligenciam, o fato de que a fome e a desnutrição, e atualmente o excesso de peso e a obesidade, são consequências, em grande medida, das desigualdades sociais e da pobreza, que impedem o acesso a uma alimentação variada e adequada à parcela da classe trabalhadora. Apesar do esforço que tem sido empreendido para se estabelecer um arcabouço teórico, metodológico e operacional, para a educação alimentar, 
nos documentos de referência que norteiam as políticas públicas ainda é possível identificar hiatos existentes entre essas referências e as ações empreendidas a nível local (SANTOS, 2012). Segundo Santos (2012), "os avanços nos discursos em torno da educação alimentar e nutricional não têm sido acompanhados ao mesmo passo no âmbito das ações locais" (SANTOS, 2012, p. 459).

A primeira versão, no Brasil, de restaurante que distribuía refeiçóes foi inaugurada, em 1939, na Praça da Bandeira, na cidade do Rio de Janeiro, capital do Brasil. Sendo uma iniciativa do Serviço Central de Alimentação, do Instituto de Aposentadorias e Pensões dos Industriários, sob a direção de Josué de Castro $^{8}$ (LABBATE, 1988). O restaurante apresentava um cardápio fixo, cujo parâmetro de planejamento apoiava-se na ciência e no total rigor técnico. Todavia, esses restaurantes não eram dirigidos ao público, e sim destinados à população trabalhadora do setor formal da indústria, comércio e bancários, instalados dentro das fábricas, alcançando basicamente o sexo masculino.

Em 1940, no âmbito do Ministério do Trabalho da Indústria e Comércio, o restaurante da Praça da Bandeira foi absorvido e ampliado pelo Serviço de Alimentação da Previdência Social (SAPS), que teve como uma de suas principais atribuições a implantação desses restaurantes, não só na capital do país, mas em outros grandes centros urbanos. Apesar de ter se estabelecido com o objetivo de ofertar refeições aos trabalhadores inseridos formalmente no mercado de trabalho, atendendo aos preceitos nutricionais e a condiçóes higiênicas adequadas, a expectativa do SAPS era estender seus serviços a toda população, tendo como alvo a família dos trabalhadores. Nesse sentido, foi prevista a realização de açóes de educação alimentar, que divulgassem informaçóes sobre o valor nutritivo dos alimentos e regras para o consumo de uma alimentação equilibrada, veiculadas através de folhetos distribuídos aos usuários (VASCONCELOS; BATISTA FILHO, 2011).

Em 1946, o Rio de Janeiro possuía sete restaurantes do SAPS, com seus usuários distribuídos em 92,58\% de homens e 7,52\% de mulheres (COSTA, 1947). O número de restaurantes em funcionamento atingiria 11 unidades em 1950, e além do Rio de Janeiro, foram instalados 42 restaurantes pelo país, sob a coordenação do governo federal. O restaurante da Praça da Bandeira chegou a atender 5.000 trabalhadores por dia (L'ABBATE, 1988). Com o fim do governo de Getúlio Vargas, as atividades desenvolvidas pelo SAPS foram descontinuadas e, em 1967, já durante a Ditadura civil-militar, no governo de Costa e Silva, o órgão foi finalmente extinto. 
Restaurantes com caráter similar voltaram a ser implantados nos centros urbanos na década de 1990. Em 1994, no Estado de Minas Gerais, e no ano de 2000, no Estado de São Paulo, esses no âmbito do Programa Bom Prato. Em 2000, o Estado do Rio de Janeiro inaugura o primeiro restaurante; o Ceará, em 2002; o Rio Grande do Norte, em 2003; a cidade de Porto Alegre, em 2005; e no Estado do Piauí, em 2006, seguindo com outras instalaçôes.

O MDS, a partir de 2004, passou a apoiar a instalação desses equipamentos públicos, com o mesmo propósito dos restaurantes já implantados nos estados, no âmbito do programa denominado Rede de Equipamentos Públicos de Segurança Alimentar e Nutricional. O programa previa, além dos restaurantes populares, a construção de cozinhas comunitárias e bancos de alimentos, como já mencionado. Ao MDS, no caso dos RP, competia o financiamento de obras de infraestrutura e instalação, bem como a compra de material permanente, em um sistema de cooperação com estados e municípios, que se encarregam da manutenção. Cabe, também, a esses parceiros federativos a avaliaçáo e o monitoramento do serviço prestado à população, principalmente, quando o gestor público faz a opção pela terceirização da operacionalização dos restaurantes. Vale destacar que a participação e o controle sociais ainda não ocorrem de forma efetiva, como seria de se esperar para uma política social.

A proposta do ministério é promover o acesso da população urbana à alimentação adequada, com prioridade aos segmentos mais vulneráveis, em situação de insegurança alimentar. Conforme requisitos estabelecidos, os restaurantes devem ter capacidade para oferecer um mínimo de 1.000 refeições ao dia (BRASIL, 2017). Portanto, o projeto dos RP se constitui como uma ação de SAN, com a expectativa de ofertar refeiçôes nutritivas a preços acessíveis, na perspectiva do DHAA. Sendo assim, é uma proposta que visa atender uma necessidade social imediata, com foco no interesse comum e geral, aspectos que se contrapóem a interesses privados e particulares, que distinguem uma política pública. Considerando, ainda, que o objetivo da política social é a garantia de um direito básico e fundamental, defende-se que programas universais são realmente mais apropriados, pois se trata da concretização de direitos. Além disso, a universalização, em contraposição à focalização, não estigmatiza, não discrimina, nem hierarquiza os beneficiados, entre os mais pobres e os menos pobres. Infere-se, pelo exposto, que características como pública, social e universal da política foram contempladas com as especificidades do programa planejado, 
restando mecanismos para que a participação e o controle social e democrático mais efetivos possam estar assegurados.

Corroborando essa avaliação, resultado de pesquisa divulgada, em 2010, e realizada com apoio do MDS, em diferentes cidades e regiôes do país, com o objetivo de identificar o perfil socioeconômico e demográfico dos usuários, apontou dados relevantes que sustentam a universalização do acesso. Na cidade do Rio de Janeiro, onde foram pesquisadas as unidades de Bonsucesso e Campo Grande, o resultado indicou que os frequentadores desses equipamentos constituem parcela da população desempregada, com alta vulnerabilidade e baixa escolaridade. Mais de $60 \%$ dos frequentadores dos restaurantes pesquisados pertencem ao grupo em situação de insegurança alimentar, entre moderada e grave, são do sexo masculino, e mais de $40 \%$ dos entrevistados mencionam não possuir renda pessoal, contingente bastante expressivo (BRASIL, 2010). Esses são dados que atestam a pertinência do programa, inclusive a opção por seu caráter universal, considerando que mesmo sendo franqueado o acesso a todos, o perfil dos frequentadores é exatamente aquele definido como prioritário pelo programa.

No Rio de Janeiro, a primeira unidade estabelecida na cidade foi o Restaurante Popular Betinho, localizado na Central do Brasil. A expectativa era atender, com acesso universal, em torno de 3.000 pessoas por dia, no horário do almoço, com a cobrança de $\mathrm{R} \$ 1,00$ por refeição. No ano de 2016 , o estado chegou a servir em torno de 37.000 almoços por dia, nos 16 restaurantes que estavam em funcionamento, cobrando o valor de $\mathrm{R} \$ 2,00$ por refeição servida (SEASDH, 2016). Nesse mesmo ano, os restaurantes foram fechados pelo governo do estado, alegando falta de recursos para a sua manutenção adiante da crise fiscal e econômica que atravessa, desde o ano de 2015. O fechamento dos restaurantes representa um duro golpe para todos aqueles que tinham o direito à alimentação parcialmente atendida pelo serviço.

\section{Premissas da política social restaurantes populares}

A contribuição efetiva desses restaurantes é amenizar a situação de insegurança alimentar (IA), que atinge a parcela mais vulnerável da população, uma necessidade imediata e urgente que deve ser prontamente atendida, embora esse acolhimento não modifique as condiçôes de vulnerabilidade dos beneficiados. Atender necessidades sociais, cuja resolução ultrapassa a iniciativa privada, individual e espontânea, sendo orientada por princípios de justiça social, deve ser a perspectiva da política social. 
Nos últimos anos, é possível verificar menores prevalências de IA nos domicílios brasileiros, cujo percentual encontrado no primeiro inquérito foi de $34,9 \%$, em 2004; 30,2\%, em 2009 (IBGE, 2010) e 22,6\%, em 2013 (IBGE, 2013). Apesar desse decréscimo, a IA ainda é alarmante, uma vez que se trata de uma violação dos direitos humanos, que pode ter repercussóes diretas e indiretas na saúde das pessoas.

Apesar dos indicadores de crescimento econômico e do avanço da ciência em todas as áreas do conhecimento, as desigualdades sociais se aprofundaram no mundo no século XX e início do século XXI (ZIEGLER, 2013). O Brasil, a despeito do declínio nos últimos anos, sempre esteve entre os países com maior índice de desigualdade social no mundo, sendo de 0,490 o valor do coeficiente de Gini, ${ }^{9}$ apurado em 2014, cujo rendimento médio mensal, dos $10 \%$ mais pobres da população, não ultrapassa o valor de R\$256,00 (IBGE, 2014). O Relatório de Desenvolvimento Humano, de 2015, do Programa das Naçóes Unidas para o Desenvolvimento (PNUD), ${ }^{10}$ indica que no Brasil 0,4\% da população está em situação de miséria extrema, 2,9\% vivem na pobreza e 7,2\% encontram-se próximos ao limiar da pobreza. O Índice de Desenvolvimento Humano ajustado à Desigualdade (IDH-D) apurado aponta que a desigualdade no país é maior que a média da América Latina.

Os restaurantes populares no Estado do Rio de Janeiro apresentavam caráter público e acesso franqueado a todos, portanto, sem critérios explícitos de focalização. Entretanto, a seletividade era definida pela limitação das pessoas atendidas e centrada na restriçáo de recursos. As prestadoras de serviço tinham limitação quanto ao número de refeiçóes servidas diariamente, recebendo do estado um complemento ao valor cobrado, equivalente a, no máximo, 3.000 almoços por dia. Dessa forma, era estabelecida uma barreira de acesso aos portadores de direitos, definido exclusivamente pela restrição de recursos ou pelo total de recursos que o estado disponibilizava para atender ao programa, ocorrendo entáo uma seletividade injusta que gerava um rebaixamento da necessidade e dos beneficiados.

A avaliação dos RP, do ponto de vista do acesso a uma refeição adequada com preços acessíveis, na perspectiva da SAN, fica normalmente restrita à etapa do processo, que se encerra na refeição consumida. Isto pressupôe que mesmo que a alimentação oferecida seja produzida em condiçóes seguras, em quantidade e qualidade adequadas e respeite os hábitos alimentares, não se pode avalizar que os princípios da SAN estejam integralmente assegurados, já que não se tem claro a 
origem do alimento que é comprado para a produção da refeição servida, portanto, das condições de cultivo e de sustentabilidade da produção.

O programa dos restaurantes populares, enquanto equipamentos de SAN, recomenda que a prioridade na aquisição de alimentos deve ser dos produtores locais, agricultura familiar. Essa preferência pode concorrer, também, com a geração de renda, conciliando iniciativas que tendem a contribuir, de maneiras distintas, para amenizar situaçôes de insegurança alimentar. Reconhece-se, entretanto, que essa recomendação não foi cumprida no Rio de Janeiro. Uma justificativa plausível para essa dificuldade se baseia no fato de a maior parte dos governos estaduais, inclusive o do Rio de Janeiro, terem optado pela terceirização da gestão desses restaurantes, o que pode impingir certa incompatibilidade de objetivos, entre contratada e contratante. Em estudo de mapeamento e caracterização de 57 restaurantes situados nos estados do Amazonas, Pará, Rio Grande do Norte, Bahia, Paraíba, Pernambuco, Ceará, Sergipe, Rio de Janeiro, Minas Gerais, São Paulo, Rio Grande do Sul, Santa Catarina, Mato Grosso, Mato Grosso do Sul, Goiás, Tocantis e Distrito Federal, verificou-se que as empresas privadas participam na operação de $25 \mathrm{RP}$, além de administrar elevado número de unidades. Em algu ma condição, como administrador ou participante na gestão da unidade, a presença de empresa privada foi identificada em 49 unidades dentre as pesquisadas (BRASIL, 2005).

As empresas que atuam como prestadoras de serviço nesse segmento se curvam obedientes aos interesses do lucro, premissa básica para sua sobrevivência frente ao sistema de mercado e forte concorrência. As prioridades das empresas são por açôes que diminuam seus custos e aumentem seus ganhos, circunstâncias que definem a escolha de fornecedores e limitam a realização de serviços que concorram para um dispêndio maior de recursos humanos e materiais, além de que as recomendaçóes em relação à aquisição de alimentos em fornecedores locais e da agricultura familiar nem sempre estão expressas e previstas nos contratos de prestação de serviços.

A gestão terceirizada, pelos motivos já elencados, também pode dificultar a participação e o controle social e democrático, que devem pautar uma política pública. As informaçóes que dizem respeito à operacionalização do serviço, pelos conselhos que têm a prerrogativa de fiscalização, como o Conselho de Segurança Alimentar e Nutricional, via de regra, não estão disponíveis, além da pouca transparência nos processos administrativos e técnicos por parte da prestadora de servços. Terceirização não é apenas a principal forma de flexibilizar o trabalho, mas 
também a principal ferramenta para a precarização econômica, social e política, que tem sido o centro da dinâmica do chamado capitalismo flexível ou acumulação flexível em tempos de hegemonia do capital financeiro (DRUCK, 2016).

Cabe ressaltar que a segurança alimentar e nutricional, como política social nos moldes como foi construída, só será assegurada através de um conjunto de açôes e programas desenvolvidos por diferentes órgãos e ministérios, de forma intersetorial, o que pode tornar os RP uma iniciativa importante e complementar. Destacase, ainda, que as características discutidas, como a universalização, o caráter público e a participação e controle sociais, não foram inteiramente observadas na operacionalização do programa.

\section{Considerações finais}

Importa observar, do ponto de vista da política social de SAN, que mesmo sendo o programa dos restaurantes populares concebido a partir dos preceitos do caráter público, da universalização do acesso e da participação e controle populares, os possíveis ou prováveis benefícios advindos da instalação dos restaurantes só se efetivarão caso sua operacionalização e gestão, sob a responsabilidade dos estados e municípios, pautem-se por tais premissas e requisitos. Nesse sentido, identificam-se dois grandes obstáculos para a perspectiva colocada.

O primeiro, a irregularidade dos recursos públicos liberados para a manutenção dos equipamentos, limitados pelo atrelamento à política fiscal instituída pelos governos, que tendem a priorizar os superávits primários, para pagamentos das dívidas públicas, em detrimentos dos gastos com políticas sociais (CASTELO, 2014). Esta prioridade determina o corte de recursos públicos em situaçóes de crise econômica, como a que o país enfrenta desde 2015, com retração do Produto Interno Bruto (PIB) e altas taxas de desemprego. As restriçôes aos gastos sociais, como consequência da política fiscal empreendida pelo governo federal, vêm sendo observadas em todas as políticas públicas, atingindo a saúde, a educação, a segurança e a SAN, que refletem na implementação das políticas sociais pelo estado. Fato que gera a imprevisibilidade na manutenção e funcionamento dos restaurantes e, consequentemente, para a contribuição aos preceitos da política social de SAN. O fechamento dos 16 restaurantes em dezembro de 2016, mantidos com recursos públicos no Estado do Rio de Janeiro, que acolhiam, prioritariamente, os grupos 
mais vulneráveis da população, é um exemplo bem ilustrativo dessa situação. A descontinuidade desse programa significa na prática abrir mão do atendimento emergencial a uma necessidade social imediata e urgente, deixando os beneficiários e usuários dos equipamentos sem a devida e necessária proteção social, principalmente na situação de penúria que encontra a população mais vulnerável.

Um segundo obstáculo, relacionado diretamente ao primeiro, é a forma de gestão dos equipamentos, via terceirização da operação. As empresas contratadas, apesar dos acordos firmados por processos licitatórios, nem sempre cumprem os contratos estabelecidos e muitas vezes não recebem dos estados pelo serviço contratado, que alegam falta de recursos, indicando náo ser uma prioridade por parte dos contratantes. Mesmo em períodos de liberação regular de recursos, a execução de açôes para além da produção e distribuição de refeições, conforme recomendação do MDS, não faz parte do universo de atribuiçóes executadas pelas prestadoras de serviço que atuam nesse segmento, como já discutido. Situação que limita significativamente a abrangência e possibilidades do programa, na expectativa de atender aos princípios evocados pela política social de SAN.

$\mathrm{Na}$ perspectiva de superar ou minimizar os obstáculos apontados, e demais percalços que possam se antepor à concretizaçáo integral do programa, e do direito, aponta-se a necessidade do fortalecimento da participação e do controle social e democrático, pelos conselhos, pelas entidades de classe que atuam nesse segmento e, em especial, por parte dos próprios usuários dos equipamentos. Este monitoramento pode ser exercido através da avaliação regular do programa, exigido como um direito, não só pelos usuários, mas também pelos movimentos sociais, entidades de classe e sindicatos de trabalhadores.

Deve-se superar a noção de uma ação assistencialista ou compensatória, dependente da vontade de governantes ou, ainda, de açôes voluntaristas. A participação e o controle social na formulação e execução da política social são pressupostos que não podem deixar de ser exercidos sob pena de descaracterizar a política social, possibilitando a debilitação dos direitos e a mercantilização da própria política (PEREIRA, 2009).

O direito social ser reconhecido não só por aqueles que se beneficiam diretamente, mas por toda sociedade, é um passo importante para efetivação de todo direito. Avalia-se que esta deve ser a maneira como o programa precisa ser percebido, o atendimento a um direito inalienável, que para ser materializado deve ser baseado 
em um consenso e assegurado pela ação do homem (HOBSBAWN, 2008). Este consenso se estende aos usuários, aos técnicos e coordenadores dos programas, aos governos e aos gestores dos restaurantes, cujas atribuiçôes são parte de uma política social que materializa um direito.

Importa destacar que, apesar dos obstáculos, o programa dos restaurantes populares reúne relevantes aspectos que o credencia como uma política social efetiva, ao se inserir em uma realidade concreta que busca atender uma necessidade humana, social e imediata. Está voltado para o interesse comum, e não individual e privado, sendo de fácil acesso e universal, sem mecanismos ou critérios de focalização. Tem como perspectiva a concretização de um direito e a proteção social. ${ }^{11}$

\section{Referências}

BEHRING, E.R. Crise do capital, fundo público e valor. In: BOSCHETTI, I. et al. (Org.). Capitalismo em crise: política social e direitos. São Paulo: Cortez, p. 44-63, 2009.

BEHRING, E. R.; BOSCHETTI, I. Política social: fundamentos e história. 7. ed. São Paulo: Cortez, 2010.

BRASIL. Ministério do Desenvolvimento Social e Combate à Fome. Instituto de Estudos, formação e Assessoria em políticas Sociais - Polis. Mapeamento e caracterização de restaurantes populares. Brasília, 2005.

. Ministério do Desenvolvimento Social e Combate à Fome. Secretaria Nacional de Segurança Alimentar e Nutricional. Rede de equipamentos públicos de alimentação e nutrição. Disponível em: <http://www.mds.gov.br>. Acesso em: 24 abr. 2017.

. Presidência da República. Lei no 11.346, de 15 de setembro de 2006. Cria o Sistema Nacional de Segurança Alimentar e Nutricional, SISAN, com vistas em assegurar o direito humano à alimentação adequada e dá outras providencias. Brasília, 2006.

. Presidência da República. Decreto no 7.272, de 25 de agosto de 2010. Diário Oficial [da] República Federativa do Brasil. Brasília: Presidência da Republica, 2010.

CASTELO, R. Crise conjuntural e (re)militarização da "questão social" brasileira. Margem Esquerda, n. 23, p. 46-51, 2014.

COSTA, D. Experiência Brasileira em restaurantes populares. Bol Oficina Sanit Panam, v. 26, n. 5, p. 415-21, 1947.

COUTINHO, C. N. Representação de interesses, formulação de políticas e hegemonia. In: TEIXEIRA, S. F. (Org.). Reforma sanitária: em busca de uma teoria. 3. ed. São Paulo: Cortez, p. 47-60, 2006. 
DRUCK, G. A terceirização sem limites: mais precarização e riscos de morte aos trabalhadores. Cad. Saúde Pública. Rio de Janeiro, v. 32, n. 6, p. 1-9, jun. 2016. Disponível em: <http://www. scielo.br/scielo.php?script=sci_arttext $\&$ pid $=$ S0102-311X2016000600502\&lng=en\&nrm $=$ iso $>$. Acesso em: 28 out. 2017.

HOBSBAWN, E. J. Mundos do trabalho: novos estudos sobre história operária. 5. ed. São Paulo: Paz e Terra, 2008.

IAMAMOTO, M. V. O Serviço Social na contemporaneidade: trabalho e formação profissional. São Paulo: Cortez, 1998.

INSTITUTO BRASILEIRO DE GEOGRAFIA E ESTATÍSTICA. Pesquisa nacional por amostra de domicílios: síntese de indicadores. Rio de Janeiro: IBGE, 2014. Disponível em: <www.ibge.gov.br/home/estatistica/populacao/trabalhoerendimento/pnad2014>. Acesso em: 8 ago. 2016.

. Pesquisa Nacional por Amostra de Domicílios: segurança alimentar, 2013. Rio de Janeiro: IBGE, 2013. Disponível em: <https://loja.ibge.gov.br/pnad-2013-seguranca-alimentar.html>. Acesso em: 3 maio 2018.

JAIME, P. C. et al. Açóes de alimentação e nutrição na atenção básica: a experiência de organização no governo brasileiro. Rev. Nutr. Campinas, v. 24, n. 6, p. 809-824, 2011. Disponível em: <http://www.scielo.br/scielo.php?script=sci_arttext\&pid=S1415-52732011000600002\&ln $\mathrm{g}=\mathrm{en} \& \mathrm{nrm}=\mathrm{iso}>$. Acesso em: 28 out. 2017.

L'ABBATE, S. As políticas de alimentação e nutrição no Brasil. I período de 1940-1964. Rev. Nutr. Campinas, v. 1, n. 2, p. 87-138, jul./dez. 1988.

LEÃO, M. M.; CASTRO, I. R. R. Políticas de alimentação e nutrição. In: KAC, G. et al. (Org.). Epidemiologia nutricional. Rio de Janeiro: Fiocruz: Atheneu, 2007, p. 519-541.

MARCONSIN, C. O cerco aos direitos do trabalho no governo Lula: um estudo crítico da reforma trabalhista. Projeto de Tese. ESS, UFRJ, Rio de Janeiro, 2007.

MONTEIRO, C. A. Pobreza, desnutrição e fome no Brasil: implicaçóes para políticas públicas. In: VELLOSO J. P. R.; ALBUQUERQUE, R. C. (Coords.). A nova geografia da fome e da pobreza. Rio de Janeiro: J. Olympio, 2004.

NETTO, J. P. Capitalismo monopolista e serviço social. São Paulo: Cortez, 1992.

PEREIRA, P. A. P. Discussões conceituais sobre política social como política pública e direito de cidadania. In: BOSCHETTI, I. et al. (Org.). Política social no capitalismo: tendências contemporâneas. 2. ed. São Paulo: Cortez, 2009, p. 87-108.

PINHEIRO, A. R. O. Reflexóes sobre o processo histórico/político de construção da lei orgânica de segurança alimentar e nutricional. Rev. Seg. Alim. e Nutric. Campinas, v. 15, n. 2, p. 1-15, 2008. 
SANTARELLI, M. Política nacional de segurança alimentar e nutricional: desafios intersetoriais e interfederativos. In: SCHINEIDER, O. F. (Org.). Segurança alimentar e nutricional: tecendo a rede de saberes. Petrópolis: De Petrus; Rio de Janeiro: FAPERJ, 2012, p. 43 - 64.

SANTOS, L. A. S. O fazer educação alimentar e nutricional: algumas contribuições para reflexão. CiênciađSaúde Coletiva. Rio de Janeiro, v. 17, n. 2, p. 207-216, 2012. Disponível em: $<$ http://www.scielo.br/scielo.php?script=sci_arttext\&pid=S1413-81232012000200018\&lng=en \&nrm=iso>. Acesso em: 6 fev. 2017.

SEASDH - SECRETARIA DE ESTADO DE ASSISTÊNCIA SOCIAL E DIREITOS HUMANOS. Restaurante cidadão. 2016. Disponível em: <http://www.seasdh.rj.gov.br/ webpopular/>. Acesso em: 18 ago. 2017.

STEIN, R.H. Crise do capital, fundo público e valor. In: BOSCHETTI, I. et al. (Org.). Capitalismo em crise: política social e direitos. São Paulo: Cortez, p. 196-219, 2009.

VASCONCELOS, F.A.G. Combate à fome no Brasil: uma análise histórica de Vargas a Lula. Rev. Nutrição. Campinas, v. 18, n. 4, p. 1-13, jul./ago. 2005. Disponível em: <http://www.scielo. br/scielo.php?script=sci_arttext\&pid=S1415-52732005000400001\&lng=en\&nrm=iso $>$. Acesso em: 6 fev. 2017.

VASCONCELOS, F. A. G; BATISTA FILHO, M. História do campo da Alimentação e Nutrição em Saúde Coletiva no Brasil. Ciênc saúde coletiva, v. 16, n. 1, p. 81-90, 2011. Disponível em: <http://www.scielo.br/scielo.php?script=sci_arttext\&pid=S1413-81232011000100012\&ln $\mathrm{g}=\mathrm{en} \& \mathrm{nrm}=\mathrm{iso}>$. Acesso em: 6 fev. 2017.

ZIEGLER, J. Destruição em massa: geopolítica da fome. São Paulo: Cortez, 2013.

\section{Notas}

${ }^{1}$ Entendemos a questão social como expressão das contradiçôes da sociedade capitalista. No sentido debatido por Iamamoto (1998), a questâo social é "apreendida como o conjunto das expressốes das desigualdades da sociedade capitalista madura, que tem uma raiz comum: a produção social é cada vez mais coletiva, o trabalho torna-se mais amplamente social, enquanto a apropriação dos seus frutos mantém-se privada, monopolizada por uma parte da sociedade" (IAMAMOTO, 1998, p. 27-28).

${ }^{2}$ No final do século XIX, o capitalismo sofre profundas modificaçôes no seu ordenamento econômico, que incidem na estrutura social e nas instâncias políticas. Esse é o período, consensualmente aceito na tradição marxista, em que o capitalismo monopolista sucede o concorrencial. "O capitalismo monopolista recoloca, em um patamar mais alto, o sistema totalizante de contradiçóes que confere à ordem burguesa os seus traços basilares de exploração, alienação e transitoriedade histórica, todos desvelados pela crítica marxiana" (NETTO, 1992, p. 15).

${ }^{3}$ Conforme Hobsbawm, do ponto de vista histórico os movimentos operários e seus movimentos associados lutaram em favor das reformas e transformaçôes sociais, exercendo um papel fundamental para estabelecer e expandir direitos, tanto individuais quanto sociais (HOBSBAWM, 2008, p. 437). 
${ }^{4}$ De acordo com Behring e Boschetti (2010), a partir dos anos 1990, com a consolidaçấo dos governos de orientação neoliberal, a "reforma" encaminhada por via tecnocrática, utilizando de forma abusiva o recurso às medidas provisórias, teve um resultado muito aquém das necessidades no atendimento às demandas sociais em se tratando da implementação eficiente das políticas públicas. "Houve uma forte tendência de desresponsabilização pela política social, acompanhada pelo desprezo pelo padrão constitucional de seguridade social" (BEHRING; BOSCEHTTI, 2010, p. 155).

${ }^{5} \mathrm{~A}$ fome e desnutrição, e mais recentemente a insegurança alimentar, são problemas persistentes no país, amplamente documentados, através de inquéritos alimentares, desde a década de 1940. A partir dos anos 1980, a tendência foi revertida, passando o país por um processo de transição nutricional. Não obstante, a fome e as carências nutricionais não foram inteiramente debeladas (MONTEIRO, 2004).

${ }^{6} \mathrm{O}$ conceito de SAN foi construído na II Conferência Nacional de Segurança Alimentar e Nutricional e ratificado pela LOSAN, prevendo que SAN é a realização do direito de todos ao acesso regular e permanente a alimentos de qualidade, em quantidade suficiente, sem comprometer o acesso a outras necessidades essenciais, tendo como base práticas alimentares promotoras de saúde, que respeitem a diversidade cultural e que sejam social, econômica e ambientalmente sustentáveis (BRASIL, 2006).

${ }^{7}$ Com a reforma ministerial promovida pelo presidente Michel Temer, após impeachment da presidente Dilma Rousseff, o Ministério de Desenvolvimento Social e Combate à Fome passa a ser denominado Ministério do Desenvolvimento Social, sendo criada uma Secretaria Especial de Agricultura Familiar e Agrária, no âmbito da Casa Civil, absorvendo as atribuições afeitas ao desenvolvimento agrário.

${ }^{8}$ Josué de Castro liderou estudos e pesquisas acerca da situação de alimentação e nutrição da população, sendo um dos precursores da Ciência da Nutrição e da consolidação das Escolas de Nutrição. Foi responsável pela abordagem política e social dada à fome e à desnutrição, avaliando-as como expressôes da questão social (L’ABBATE, 1988).

${ }^{9} \mathrm{O}$ índice Gini é um indicador de desigualdade social, calculado a partir de uma escala que varia de 0 a 1. Quanto mais próximo o indicador estiver de 1, mais desigual é a distribuiçâo de renda e riqueza no país.

${ }^{10}$ Programa das Naçóes Unidas para o Desenvolvimento (PNUD, 2014). Disponível em: <www.pnud. org.br>. Acesso em: 4 ago. 2016.

${ }^{11}$ S. M. Padrão e O. B. de Aguiar foram responsáveis pela concepção, desenho do ensaio, redação e revisão final do artigo. 


\section{Abstract}

\section{Popular restaurants: social policies under debate}

Public social policies are recognized, in this paper, as imperative, in capitalist societies, to enforce rights and fulfill human needs. In Brazil, and also in other capitalist countries, social policies were developed as a result of class struggle. However, when dependent on the release of public funds, these policies can be discontinuous. In terms of social policies, and in the context of food and nutritional security, Brazil's Network of Public Facilities for Food and Nutritional Security and, particularly, the so-called popular restaurants, are aimed at providing the urban population with access to adequate food at affordable prices, thus giving priority to the most vulnerable people. The restaurants were originally created in the 1940s, and they are still being used to minimize political, social and economic imbalances. The effective contribution of these restaurants is to mitigate the situation of food insecurity. However, the irregular availability of public funds and the limited participation and control of society can compromise the implementation of this social policy and the fulfillment of the human right to food. Therefore, the shutdown of 16 restaurants, in 2016, in Rio de Janeiro, meant to relinquish the provision of emergency care and social protection.

> Keywords: public policy; Food and Nutrition Security; restaurants; public sector; food assistance. 